\title{
Microplastic extraction protocols can impact the polymer structure
}

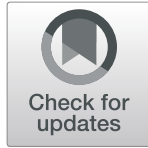

Patrizia Pfohl ${ }^{1}$, Christian Roth${ }^{1}$, Lars Meyer ${ }^{1}$, Ute Heinemeyer ${ }^{1}$, Till Gruendling ${ }^{1}$, Christiane Lang ${ }^{1}$, Nikolaus Nestle , Thilo Hofmann ${ }^{2}$, Wendel Wohlleben ${ }^{1}$ and Sarah Jess $\left.\right|^{1,3^{*}}$ (D)

\begin{abstract}
Although microplastics are ubiquitous in today's natural environments, our understanding of the materials, quantities, and particle sizes involved remains limited. The recovery of microplastics from different types of environmental matrices requires standardized matrix digestion protocols that allow inter-laboratory comparisons and that have no effect on the polymers themselves. A number of commonly used digestion methods rely on oxidation with concentrated hydrogen peroxide solutions to remove organic matter from the matrix. However, this can alter the nature of polymers through hydrolysis and often does not lead to a complete matrix removal. We have therefore investigated the use of two altered matrix digestion protocols, an acidic (Fenton) protocol and a new alkaline (Basic Piranha) protocol, focusing mainly on the effect on biodegradable polymers (polylactide, polybutylene adipate terephthalate, polybutylene succinate) and polymers with known degradation pathways via hydrolysis (thermoplastic polyurethanes, polyamide). Comparing the initial surface textures, chemical compositions, and particle size distributions with those obtained after digestion revealed that the Fenton protocol left most of the polymers unchanged. The ferrous residue that remains following Fenton digestion had no effect on either the polymer composition or the particle size distribution, but could disturb further analytics (e.g. Raman microscopy due to auto-fluorescence). While increasing the chance of complete matrix removal, the more powerful Basic Piranha protocol is also more likely to affect the polymer properties: Polylactide polymers in particular showed signs of degradation under alkaline digestion (reduced polylactide content, holes in the polymer matrix), indicating the unsuitability of the Basic Piranha protocol in this specific case. Polyamide, however, remained stable during the Basic Piranha treatment, and the surface chemistry, the particle size as well as the molar mass distribution of the investigated thermoplastic polyurethanes were also not affected. Hence, this protocol offers a powerful alternative for microplastic analysis with focus on particle size in more complex environmental matrices (e.g. removal of cellulose in soil), while avoiding ferrous Fenton residue. Unexpectedly, also tire rubber, a frequent target analyte in microplastic monitoring, was found to be susceptible to artefact structures by both oxidation protocols. In summary, controls for the specific combination of polymer and sample preparation protocol are highly recommended to select the most fitting protocol. Here selected suitable combinations are reported.
\end{abstract}

Keywords: Microplastics, Extraction, Organic matrix digestion, Polymer stability, Fenton, Oxidation, Biodegradable polymer blends, Basic Piranha, Hydrolysis

\footnotetext{
* Correspondence: sarah.jessl@tum.de

'BASF SE, Carl-Bosch-Str. 38, 67056 Ludwigshafen, Germany

${ }^{3}$ Present address: Technical University Munich, Arcisstrasse 21, 80333 Munich,

Germany

Full list of author information is available at the end of the article
}

\section{Springer Open}

(c) The Author(s). 2021 Open Access This article is licensed under a Creative Commons Attribution 4.0 International License, which permits use, sharing, adaptation, distribution and reproduction in any medium or format, as long as you give appropriate credit to the original author(s) and the source, provide a link to the Creative Commons licence, and indicate if changes were made. The images or other third party material in this article are included in the article's Creative Commons licence, unless indicated otherwise in a credit line to the material. If material is not included in the article's Creative Commons licence and your intended use is not permitted by statutory regulation or exceeds the permitted use, you will need to obtain permission directly from the copyright holder. To view a copy of this licence, visit http://creativecommons.org/licenses/by/4.0/. 


\section{Introduction}

The global production of plastics in 2018 reached 359 million tonnes [1] which sparks an increasing concern about microplastic pollution; specifically regarding possible hazards and risks to the environment and to human health [2-5]. Microplastics are defined as solid plastic particles smaller than $5 \mathrm{~mm}[6,7]$. In December 2015 the U.S. government enacted a public law to restrict the addition of microplastics to rinse-off cosmetic products, in order to prevent their eventual release into the environment after application [8]. The European Chemical Agency (ECHA) published a restriction proposal for microplastics deliberately added to consumer products in January 2019 [9]. These primary microplastics are already within the defined size range from the beginning of their lifecycle; secondary microplastics result from the fragmentation of macroplastics, but are not yet included in the proposed ECHA restriction $[6,10]$. A possible derogation in the restriction is the use of biodegradable polymers to encourage the development and use of biodegradable alternatives $[9,11]$.

Plastics and microplastic particles have been reported in a whole range of environmental matrices such as soils, $[12,13]$ sediments, composts, and aqueous media [3, $12-15]$ including marine, $[15,16]$ freshwater, $[17,18]$ waste water, $[14,19]$ and sewage sludge systems $[20,21]$. High levels of uncertainty remain, however, concerning the materials, quantities, and particle sizes involved. Methods for microplastic extraction and analysis are yet to be standardized, which is one reason for these high levels of uncertainty [15, 17, 22]. Extraction protocols currently rely on sieving, density separation, and organic matrix digestion (Fig. 1a), [19, 20, 23-25] with the matrix digestion being one of the most critical steps. The digestion protocol can affect polymers depending on the chemicals used (Fig. 1b), [25-27] resulting in the degradation, fragmentation, and/or dissolution of particles and thereby having a significant influence on analytical results.

Matrix digestion protocols previously reported include acidic oxidation with Fenton reagent (using hydrogen peroxide as an oxidant and iron (II) as a catalyst) $[19,28-30]$ and alkaline oxidation using, for example, potassium hydroxide $[24,31]$ or sodium hydroxide [32]. Hydrogen peroxide is often used to remove organic matter [31, 33, 34]. Basic Piranha (a combination of hydrogen peroxide and ammonia) [35-38] is a possible alternative and stronger oxidizing reagent that leaves no ferrous residue, unlike the Fenton reagent [19, 28-30]. Enzymatic digestion is also often used [39, 40], but when targeting fragments of biodegradable polymers that are deliberately designed to be degraded by enzymes the use of enzymes for their extraction would be disadvantageous.
Although hydrogen peroxide oxidation is known to affect polyamide (PA) and polystyrene particles, $[18,25$, 34] the resulting changes in polymer properties have barely been investigated. Only a limited number of investigations have focussed on the influence of oxidation on particle properties, mostly on particles of common polymers such as polyethylene, [25, 31, 33] polypropylene, [34] polyamide, [41] polyvinyl chloride, [41] and polystyrene $[26,31]$. While polyolefins appear to be resistant to oxidizing agents, polyamides have been shown to be affected under certain conditions [25, 42]. Hurley et al. documented a loss in particle size of $33.4 \pm 47.2 \%$ following treatment with $30 \%$ hydrogen peroxide solution at $70^{\circ} \mathrm{C}$ [25]. However, the results of investigations into polymer oxidation stability that have considered only polymer pellets and no powders may be biased, [25, $39,43]$ since powders are likely to be more susceptible to alteration due to their higher specific surface areas.

Time-efficient matrix digestion protocols are required that will minimize polymer alteration in as large a range of polymer types as possible. However, the oxidation stability of biodegradable polymer blends and thermoplastic polyurethanes (TPUs) during microplastic extraction processes has yet to be investigated. Furthermore, large quantities of tire rubber particles are also present in the environment and these do not consist of pure polymers but also contain a number of different additives and nanomaterials $[44,45]$. Such complex compositions suggest that any analysis should not be based solely on the chemical composition of the polymers but also needs to take into account the additives: Matrix digestion protocols could initiate leaching or transformation of those additives, leading to changes in particle properties. Due to the large amount of additives (e.g. nanoscale carbon black) contained in tire rubber, the environmental and human health effects of those additives might be equally important as the effects of the microplastic particles themselves [44]. Biodegradable materials are designed to decompose completely within a specific environment, which is why they are more susceptible to degradation pathways in general $[46,47]$. Al-Azzawi et al. reported first insights into the stability of polylactide in common digestion protocols [48], but data on biodegradable polymer blends with different components is still missing. Here the microstructure within the blend may change from inadvertent selective etching during the sample preparation. TPU materials are polymers with a large variety of chemical compositions due to the range of possible constituents. Degradation pathways via hydrolysis are known: Concentrated acids and alkaline solutions usually affect TPUs, with polyester TPUs being less stable than polyether TPUs and only tolerating very brief contact with dilute acids and bases, at room temperature $[49,50]$. 


\section{a Microplastic extraction process}

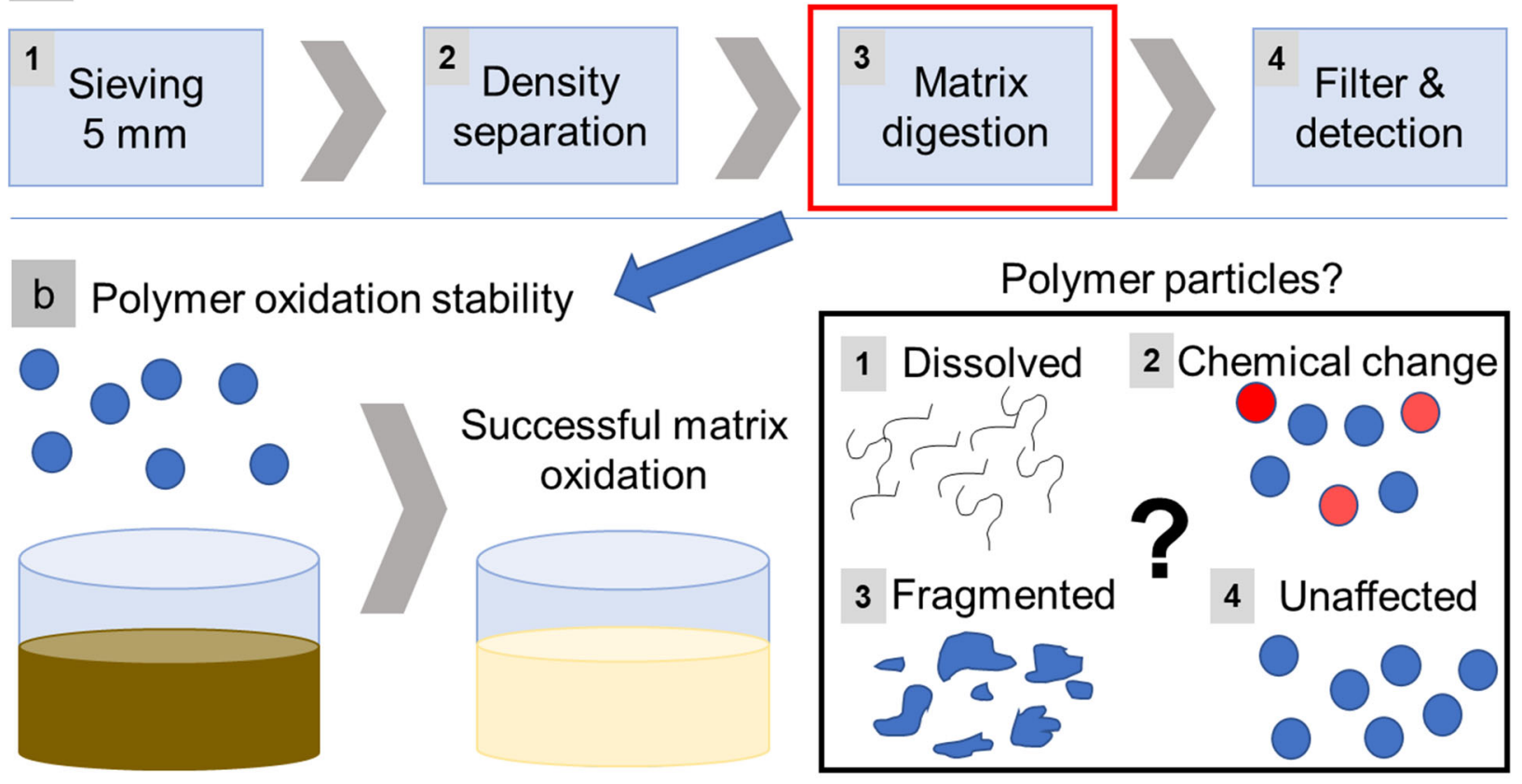

\section{Polymers used in this study}

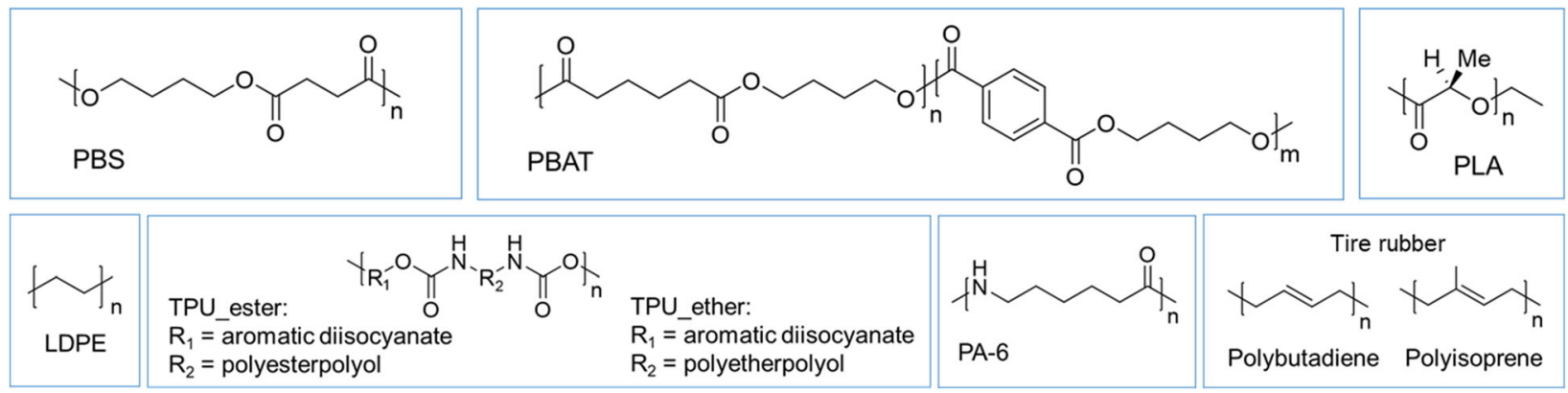

Fig. 1 Microplastics extraction process. a Common steps in extraction processes: sieving removes a large proportion of the matrix, density separation removes the heavy inorganics, and matrix digestion removes the organics. $\mathbf{b}$ Possible states of microplastic particles in the matrix after aging processes in natural environments and/or after matrix digestion: they can dissolve, fragment, or undergo chemical alteration. c Chemical structures of polymers used in this study: microplastics show different stabilities with different digestion protocols, depending on their polymer backbone

The choice of extraction protocol is a crucial aspect of the quantification of microplastics in natural environments. We therefore investigated the impact of a wellknown acidic (Fenton) and a new powerful alkaline (Basic Piranha) oxidation on the properties of three different categories of polymer powders: (I) biodegradable polymer blends, (II) engineering plastics such as PAs and TPUs that have possible degradation pathways via hydrolysis and have not previously been investigated in detail, and (III) tire rubber, as one of the main sources of microplastics with complex compositions that are found in natural environments [6]. Low density polyethylene (LDPE) was used as a resistant reference material (Fig. 1c).

\section{Materials \& methods}

\section{Materials}

The influence of oxidation processes on microplastic particles was investigated for eight different polymers: three different biodegradable polymer blends (PLA_based, PBAT_based, and PBS_based), two types of thermoplastic polyurethane (TPU_ester, TPU_ether), polyamide-6 (PA6), tire rubber, and low density polyethylene (LDPE) as a reference material. The focus for the TPUs was on a comparison between ester and ether based polyols, with the diisocyanate component being aromatic in both cases.

The polymer particles were obtained by cryo-milling granules and sieving $(80 \mu \mathrm{m}, 250 \mu \mathrm{m}, 315 \mu \mathrm{m}$, and $1 \mathrm{~mm}$ 
sieve sizes, depending on the polymer type) to obtain suitably small particles. The additional sieving step was included to obtain a cut-off for the larger particles that might still be present after milling. The tire rubber particles were directly acquired from MRH (Mülsener Rohstoff- und Handelsgesellschaft mbH, Mülsen, Germany). Details, suppliers and images of the investigated particles are provided in the Supporting Information (SI Figure 1, SI Table 1).

For each of the oxidation protocols investigated a $2 \mathrm{~g}$ sample of each sieved polymer powder (sizes according to SI Table 1) was placed in a clean glass jar and digestion reagent was added. Following the reaction after two hours, the particles were filtered using a $0.5 \mu \mathrm{m}$ glass fiber filter, rinsed with ultrapure water, and dried at $40{ }^{\circ} \mathrm{C}$. The microplastic particles were analyzed regarding their surface chemistry, texture and particle size distribution at the start of the investigations and again following their exposure to the digestion reagents. Duplicate samples were prepared for each oxidation protocol.

\section{Fenton oxidation}

Fenton oxidation is a well-known process for removing organic matter from environmental matrices [19, 28-30]. We investigated the effect of the Fenton reagent on polymer particles without any environmental matrix. The experiments were performed using a hydrogen peroxide concentration of $250 \mathrm{~g} / \mathrm{L}$ ( $30 \% \mathrm{w} / \mathrm{w}$, diluted with ultrapure water to the desired concentration) and an iron (II) sulphate concentration of $2.5 \mathrm{~g} / \mathrm{L}$. [19, 29, 30, 51] Sodium hydroxide was used to adjust the $\mathrm{pH}$ to 3 , as this has previously been found to be an ideal $\mathrm{pH}$ for Fenton reactions $[19,28,52]$. The experiment was performed under ambient temperatures [30, 52].

\section{Basic Piranha oxidation}

We investigated the effects of alkaline oxidation by treating polymer powders with a combination of hydrogen peroxide and ammonium hydroxide according to the Basic Piranha protocol, which is based on the silicon wafer cleaning method with hydrogen peroxide developed by W. Kern et al. [35, 37] The ammonium hydroxide converts the mildly oxidizing hydrogen peroxide into a more aggressive oxidizing agent [36, 53]. Fig. 2 shows a comparison of these two protocols on sludge retrieved from the local waste-water treatment facility (Bad Dürkheim) as a real-world environmental matrix. Compared to the well-known Fenton oxidation, with Basic Piranha one obtains a lower amount of oxidation residue precipitating after the reaction (Fig. 2). Ferrous Fenton residue can disturb further analytics (e.g. Raman microscopy due to auto-fluorescence [54]). In this regard, the Basic Piranha protocol is superior to Fenton protocols which motivated us to try out this protocol. The Basic Piranha experiments were performed using a hydrogen peroxide concentration of $125 \mathrm{~g} / \mathrm{L}(30 \% \mathrm{w} / \mathrm{w}$, diluted with ultrapure water to the desired concentration) and an ammonium hydroxide concentration of $105 \mathrm{~g} / \mathrm{L}(25 \% \mathrm{w} / \mathrm{w})$. A less aggressive mixture was used for the biodegradable polymers, with a hydrogen peroxide concentration of 50 $\mathrm{g} / \mathrm{L}$ and an ammonium hydroxide concentration of $40 \mathrm{~g} /$ $\mathrm{L}(25 \% \mathrm{w} / \mathrm{w})$. The temperature was maintained at $70^{\circ} \mathrm{C}$, $\mathrm{pH}=10$.

\section{Scanning electron microscopy (SEM)}

Scanning Electron Microscopy was used to compare the surface textures of the polymer powder grains before and after digestion. The powder particles were fixed onto Leit-C-plast tape on a standard SEM stub and coated with $8 \mathrm{~nm}$ platinum. The measurements were performed with a Zeiss Gemini 500 SEM that was operated at $3 \mathrm{kV}$, using secondary electrons for improved topography contrast. The inorganic residue left on the particle surfaces following Fenton treatment was also investigated using back scattered electrons (BSE, material contrast) at $5 \mathrm{kV}$ and energy dispersive $\mathrm{X}$-ray spectroscopy

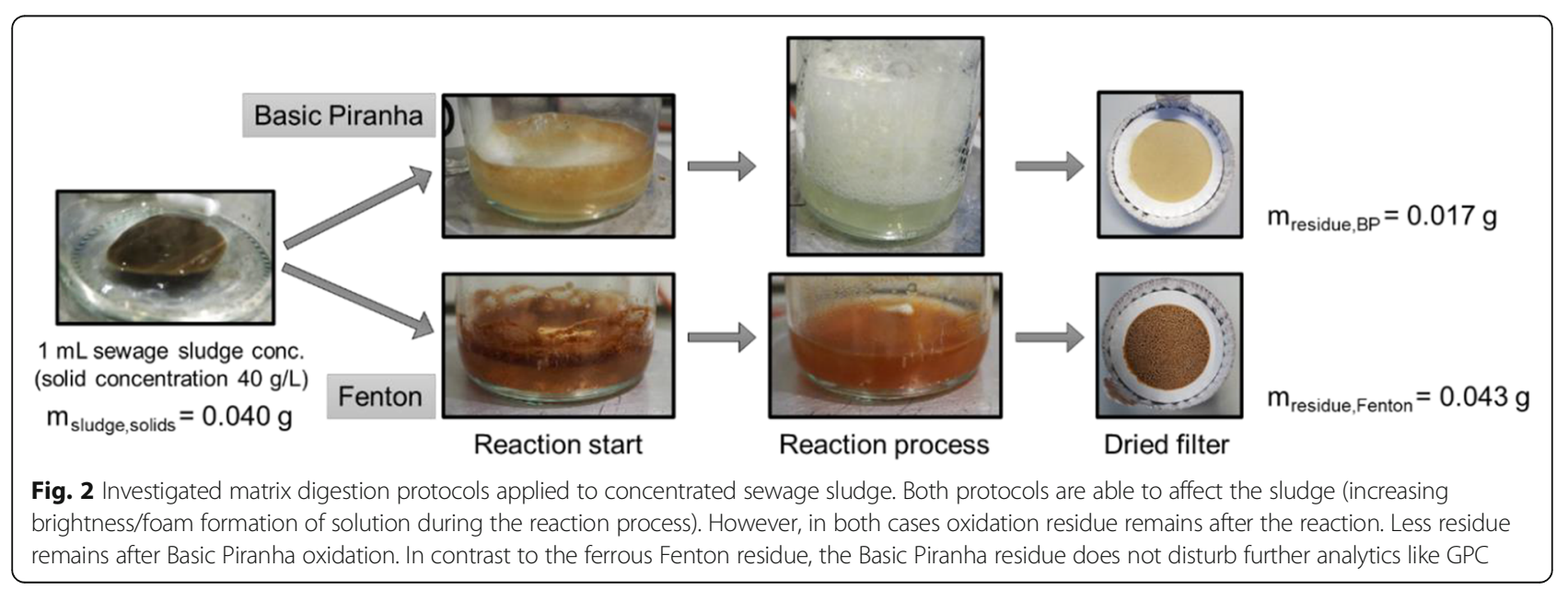


(EDXS, chemical analysis) at $15 \mathrm{kV}$. For these investigations the particle surfaces were first coated with $10 \mathrm{~nm}$ carbon.

\section{Fourier-transform infrared spectroscopy (FT-IR)}

The chemical composition of the polymer surfaces before and after treatment were analyzed by FT-IR spectroscopy and any spectral changes investigated. The chemical compositions were determined using a ThermoFisher IS50 FT-IR spectrometer with a diamond ATR accessory (IS50-ATR). The FT-IR spectra were recorded in the region of $4000-400 \mathrm{~cm}^{-1}$ with 32 scans at a resolution of $4 \mathrm{~cm}^{-1}$.

\section{Fraunhofer light scattering}

The particle size distributions for the polymer powder particles were determined before and after oxidation using a Mastersizer 3000 (MV Hydro unit) with evaluation software conforming to ISO13320 and a measuring accuracy of $0.6 \%$ [55]. An internal standard operating procedure for measuring the sizes of microplastic particles was followed. The sample volume was determined by adjusting the light shading range to between 5 and $16 \%$. The surfactant Nekanil 910 was added to the sample which was then subjected to ultrasonication for 125 s. 10 measurements per sample were obtained over $10 \mathrm{~s}$ periods.

\section{Gel permeation chromatography (GPC)}

The molar mass distributions of the studied polymers before and after Basic Piranha oxidation were determined by Gel Permeation Chromatography (GPC), using a modular GPC system with a combination of columns (HFIP-LG Guard column, 2 x PL HFIPgel columns, $300 \times 7.5 \mathrm{~mm}, 3-100 \mu \mathrm{m}$, Agilent) and a refractive index detector $(8 \mu \mathrm{l}$, Agilent). The temperature was set to $35^{\circ} \mathrm{C}$ and the flow rate to $1.0 \mathrm{~mL} / \mathrm{min}$. Calibration was conducted using a polymethylmethacrylate calibration kit (with a known molar mass distribution) and 12 calibration points. Approximately $6 \mathrm{mg}$ of each sample was dissolved in approximately $4 \mathrm{~mL}$ eluent $(1,1,1,3,3,3$ Hexafluoro-2-propanol, Alfa Aesar) over $5 \mathrm{~h}$ on a shaking table at room temperature. The resulting solutions were filtered through Millipore-Millex-FG $0.2 \mu \mathrm{m}$ filters prior to injection.

\section{X-ray microtomography $(\mu-C T)$}

The macroscopic shape of the powder grains was examined by X-ray $\mu$-CT before and after treatment using a Bruker Skyscan $1172 \mu$-CT system (Bruker Skyscan, Antwerp, Belgium) equipped with a $10 \mathrm{~W} \mathrm{X}$-ray generator with a maximum acceleration voltage of $100 \mathrm{kV}$ (Hamamatsu, Hamamatsu Japan) and an 11 MPixel Xray camera (Ximea, Münster, Germany). Samples of the treated and untreated powders were inserted into $\mathrm{PE}$ vials with $8 \mathrm{~mm}$ outer diameters and X-ray $\mu$-CT scans carried out using unfiltered $\mathrm{X}$-rays with an energy level of $40 \mathrm{keV}$ and a voxel size of $1.96 \mu \mathrm{m}$.

\section{Results and discussion}

Basic Piranha oxidation does affect biodegradable polymers, Fenton oxidation only induces small changes in their particle size distribution

Following Basic Piranha oxidation the surface of the polylactide (PLA) based polymer blend showed degradation of the polymer matrix (Fig. 3.1a), leaving only filamentous and spherical micro- and nanostructures. The Basic Piranha treatment also led to the formation of small holes in the matrix of the polybutylene adipate terephthalate (PBAT) based polymer blend (Fig. 3.1b), and larger holes in the polybutylene succinate (PBS) based polymer blend (Fig. 3.1c).

FT-IR spectra for these biodegradable polymers revealed an either partially or totally reduced PLA content following Basic Piranha oxidation. For the PLA-based polymer blend (Fig. 3.2a) the ratio of the PLA peak at $1750 \mathrm{~cm}^{-1}$ ( $\mathrm{C}=\mathrm{O}$ vibration) to the peak at $1715 \mathrm{~cm}^{-1}$ ( $\mathrm{C}=\mathrm{O}$ vibration) changed from $12: 10$ prior to Basic Piranha oxidation to $3: 10$ after oxidation, reflecting the reduction in PLA content. The initial PLA content of the PBAT-based polymer blend, prior to oxidation, was low: the ratio of the PLA peak at $1760 \mathrm{~cm}^{-1}(\mathrm{C}=\mathrm{O}$ vibration) to the PBAT peak at $1710 \mathrm{~cm}^{-1}(\mathrm{C}=\mathrm{O}$ vibration) was 2:10 (Fig. 3.2b) prior to Basic Piranha oxidation but the PLA peak disappeared completely following oxidation, indicating complete degradation of the PLA component. For the PBS-based polymer blend, the ratio of the PLA peak at $1760 \mathrm{~cm}^{-1}$ ( $\mathrm{C}=\mathrm{O}$ vibration) to the PBS peak at $1710 \mathrm{~cm}^{-1}(\mathrm{C}=\mathrm{O}$ vibration) was $7: 10$ (Fig. $3.2 \mathrm{c}$ ) prior to Basic Piranha oxidation and the PLA peak again disappeared after oxidation, indicating the degradation of larger quantities of PLA.

Basic Piranha oxidation reduced the particle sizes for the PLA-based and PBS-based polymer blends (Fig. 3.3a + c, SI Table 2a). The shape of the particle size distribution curve for the PLA-based blend (Fig. 3.3a) reveals an increase in the proportion of smaller particles following Basic Piranha oxidation, resulting in a slightly bimodal distribution: the percentage change in the average particle size (Dx50, or cumulative $50 \%$ point of diameter) of the PLA-based particles following oxidation was $45.8 \pm 14.3 \%$. Average particle sizes on their own do not provide enough information to reveal these changes and thus need to be considered in combination with the size distribution curves. The molar mass distributions (determined by GPC) before and after Basic Piranha oxidation also show similar patterns, with a reduction in the molar masses for the biodegradable polymer blends 


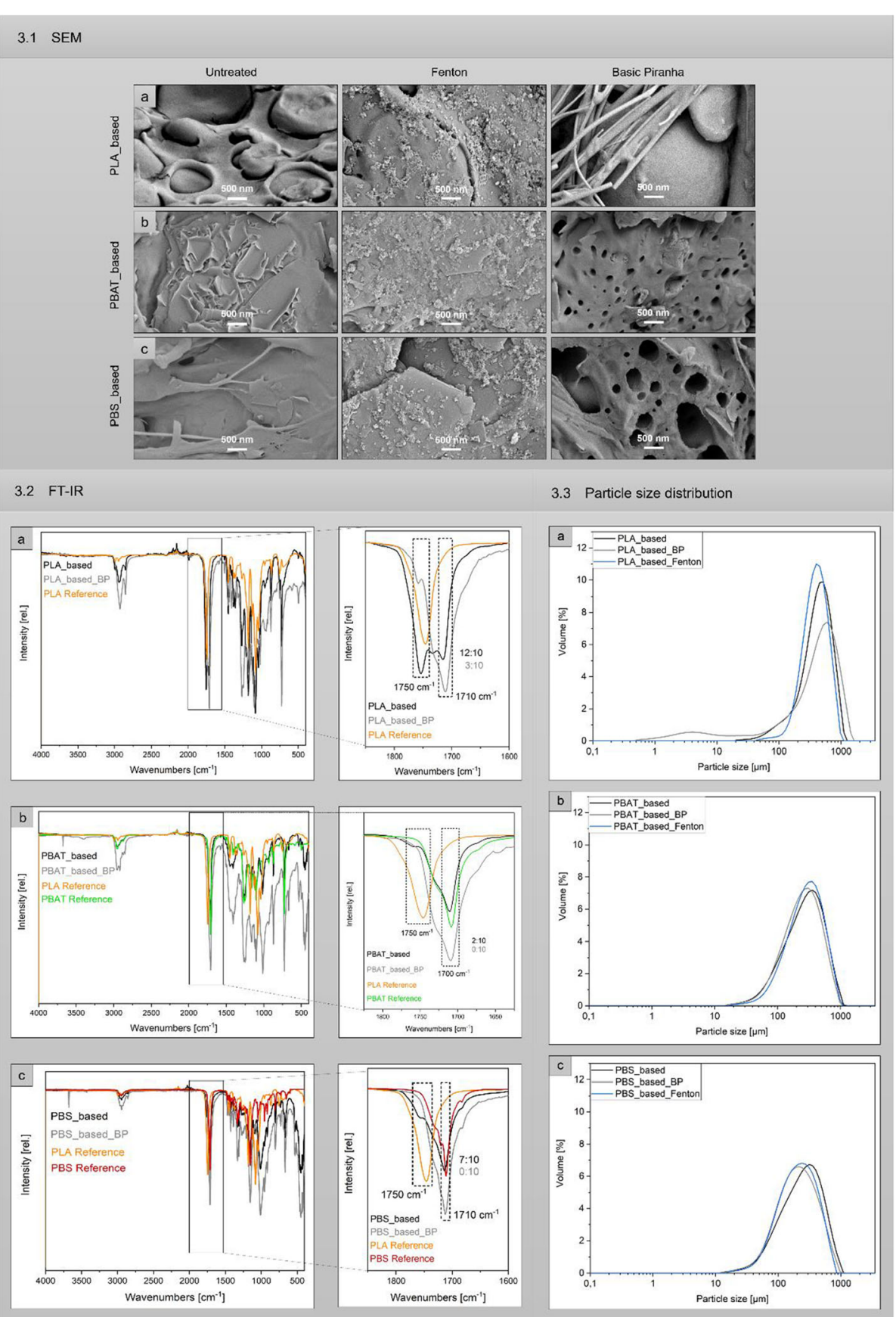

Fig. 3 Properties of biodegradable polymer blends before and after Fenton and Basic Piranha oxidation. (3.1) SEM images, (3.2) FT-IR spectra, (3.3) Particle size distributions for (a) PLA_based, (b) PBAT_based, and (c) PBS_based polymer blends (BP: oxidation with Basic Piranha. Fenton: oxidation using the Fenton protocol). The polymer particles were clearly affected by Basic Piranha oxidation but showed no significant change following Fenton oxidation

following oxidation (SI Figure 5a-c). The PLA-based polymer blend showed a bimodal distribution similar to that in the particle size distribution (SI Figure 5a).

Polymers based on PLA are more commonly degraded by hydrolysis rather than by microbial attack [56], which means that they are susceptible to alkaline attack. Such materials also have a low heat resistance which could lead to problems with Basic Piranha oxidation due to the higher temperatures involved $[46,47,56]$. PBAT is a strong, flexible aromatic-aliphatic polyester almost as resistant as LDPE. Although its aromatic unities lead to improved mechanical properties, biodegradation is still 
possible if the aromatic content is low [46, 47, 57, 58]. PBS is an aliphatic polyester that is most commonly attacked by enzymatic hydrolysis, but chemical hydrolysis is also possible $[46,47]$. Furthermore, the PBATbased and PBS-based polymer blends also contain the degradable, poorly stabilized PLA, which is highly susceptible to hydrolysis $[46,47,56]$. The PLA content in the PBS-based blend, which had the larger holes in the matrix following oxidation, was $12 \%$ higher than in the PBAT-based blend, which is the blend with the smallest proportion of the poorly stabilized PLA component. This corresponds with the oxidation stability results, which indicated that the PBAT-based blend was the least affected.

In contrast to the Basic Piranha protocol, the Fenton protocol did not result in any visible changes to the surfaces of the biodegradable polymer particles (Fig. 3.1a-c), except for some nanostructured particles identified as ferrous Fenton residue by BSE imaging and EDXS (SI Figure 4). Furthermore, FT-IR spectra did not reveal any changes to the chemical compositions of the biodegradable polymers following Fenton oxidation (SI Figure 10).

Fenton oxidation did, however, result in a reduction in the particle sizes (up to 11.7\%) of the biodegradable polymers (Fig. 3.3a-c, SI Table 2b). Especially the PLA_ based particles smaller than $100 \mu \mathrm{m}$ disappeared in the curve (Fig. 3.3a). The particle sizes of PBS_based were equally affected by Fenton $(-11.7 \pm 1.1 \%)$ and Basic Piranha $(-14.9 \pm 1.0 \%$ ) oxidation (Fig. 3.3a + c, SI Table $2 \mathrm{~b}$ ). Even though the size-reductions and changes in the case of Fenton oxidation were less than those observed following Basic Piranha oxidation (especially for the PLA-based polymer blend), changes in particle sizes are of great significance if particle sizes are in focus for microplastic analytical questions.

Our results, therefore, clearly indicate that the investigated polymers are less affected by the Fenton oxidation, but the Basic Piranha oxidation can affect certain components of the polymers, in particular the relatively unstable PLA component. Although the surface texture and chemistry of the biodegradable polymer blends remained unaffected by the Fenton protocol, researchers should be aware of the induced changes in the particle size distribution when analyzing particle counts and sizes after an extraction process based on Fenton oxidation.

\section{Basic Piranha oxidation affects only the surface textures of TPU particles, while PA-6 remains unaffected}

The Fenton protocol had no visible effect on the surface textures of either of the two types of TPU. There were slight changes in the surface textures of the TPU_ester, but none in those of the TPU_ether. In contrast, the Basic Piranha protocol had an effect on the surface textures of both of these polymers (Fig. 4.1a $+\mathrm{b}$ ). The TPU_ether was more affected then the TPU_ester but rough structures on the polymer surface became visible both cases, that were not present in the untreated samples. Researchers should avoid such changes in the surface texture induced by the digestion protocol, since they could be confused with distinctive characteristics being present in the original particles. However, the FTIR spectra showed no changes to the chemical compositions following either of the oxidation protocols (Fig. $4.2 \mathrm{a}+\mathrm{b}$ ), nor were there any changes in the particle size distributions or molar mass distributions (Fig. 4.3a + b, SI Table 2, SI Figure 5). Since aromatic polyurethanes contain hydrophobic phenyl groups, they are unlikely to absorb aqueous media and hydrolysis will therefore generally only occur at higher temperatures, such as during Basic Piranha oxidation [59, 60]. The TPU_ester tends to be more stable during oxidation than the TPU_ether, although we noted that the stability was dependent on the oxidation conditions, with the TPU_ester being less stable under acidic oxidation and the TPU_ether less stable under alkaline oxidation. These results are in accordance with literature: Scholz et al. reported the stability of ester/ether-based TPUs in various environmental scenarios and concluded a higher stability of the esterbased TPUs in general [61]. An exemption of this observation appears to be the stability of TPU-esters in weak acids: In addition to our observations, tests for the chemical resistance of known BASF TPU materials show that the ester-based TPUs are stable in weak acids for days and weeks, whereas the ether-based TPUs are even stable for months and years [62].

Some researchers have noted fragmentation and degradation of polyamides under specific acidic and alkaline conditions [25, 42]. Due to the interchain hydrogen bonds between the amide groups, polyamide has a high crystallinity and a high cohesive energy density. Polyamides are therefore resistant to swelling and dissolution in hydrocarbons but could be attacked by mineral acid, depending on its concentration [50, 63]. Neither the Fenton nor Basic Piranha protocols had any effect on the surface texture, chemical composition, particle size, or molar mass distribution of PA-6 particles (Fig. 4.1-3c, SI Table 2, SI Figure 5). Residues of iron (II) sulphate were present in the supernatant of the PA-6 sample (only), following Fenton oxidation. The two significant peaks at $1100 \mathrm{~cm}^{-1}$ and $615 \mathrm{~cm}^{-1}$ are due to the sulphate vibrations (SI Figure 6) [64].

While Hurley et al. reported that hydrogen peroxide at $70^{\circ} \mathrm{C}$ had a major influence on polyamide granules, resulting in their fragmentation into small particles, [25] we have not been able to confirm this observation. Cole et al. reported structural damage to polyamide fibres under alkaline conditions $\left(10 \mathrm{M} \mathrm{NaOH}\right.$ at $\left.60^{\circ} \mathrm{C}\right)$, [42] 

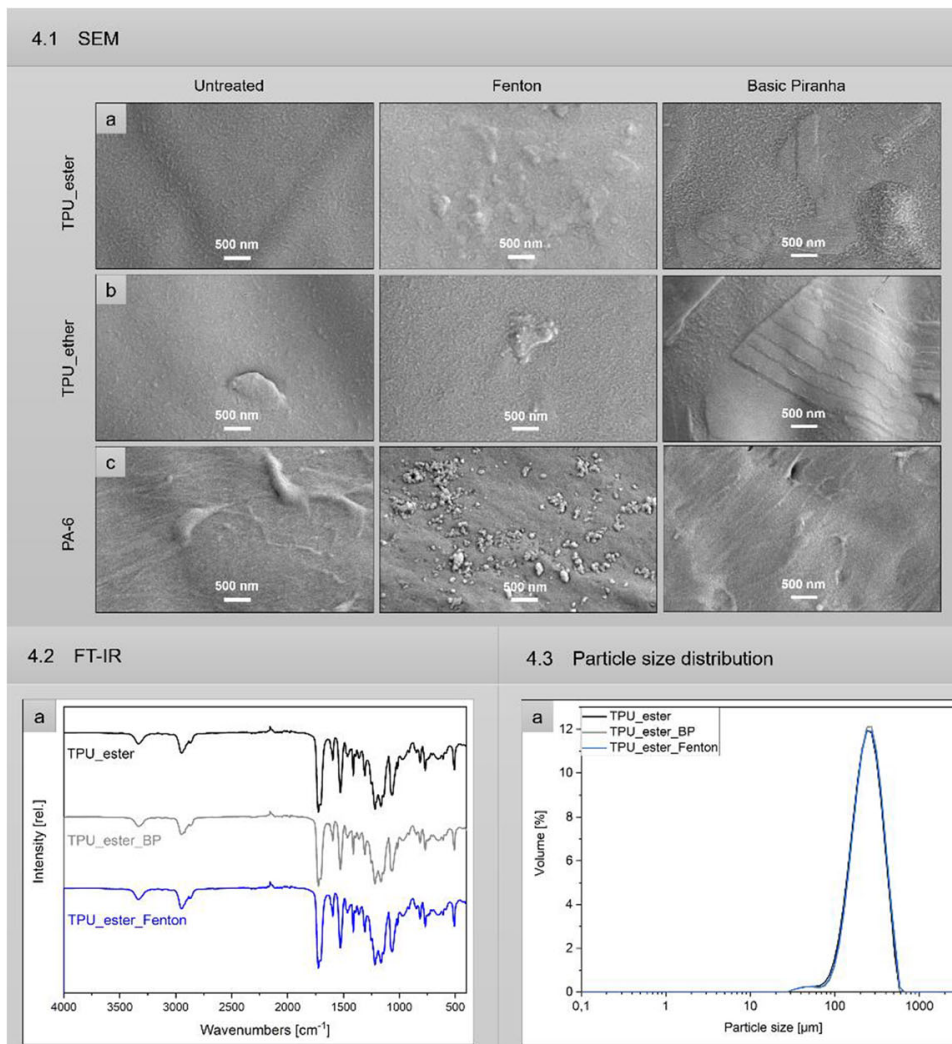

4.3 Particle size distribution
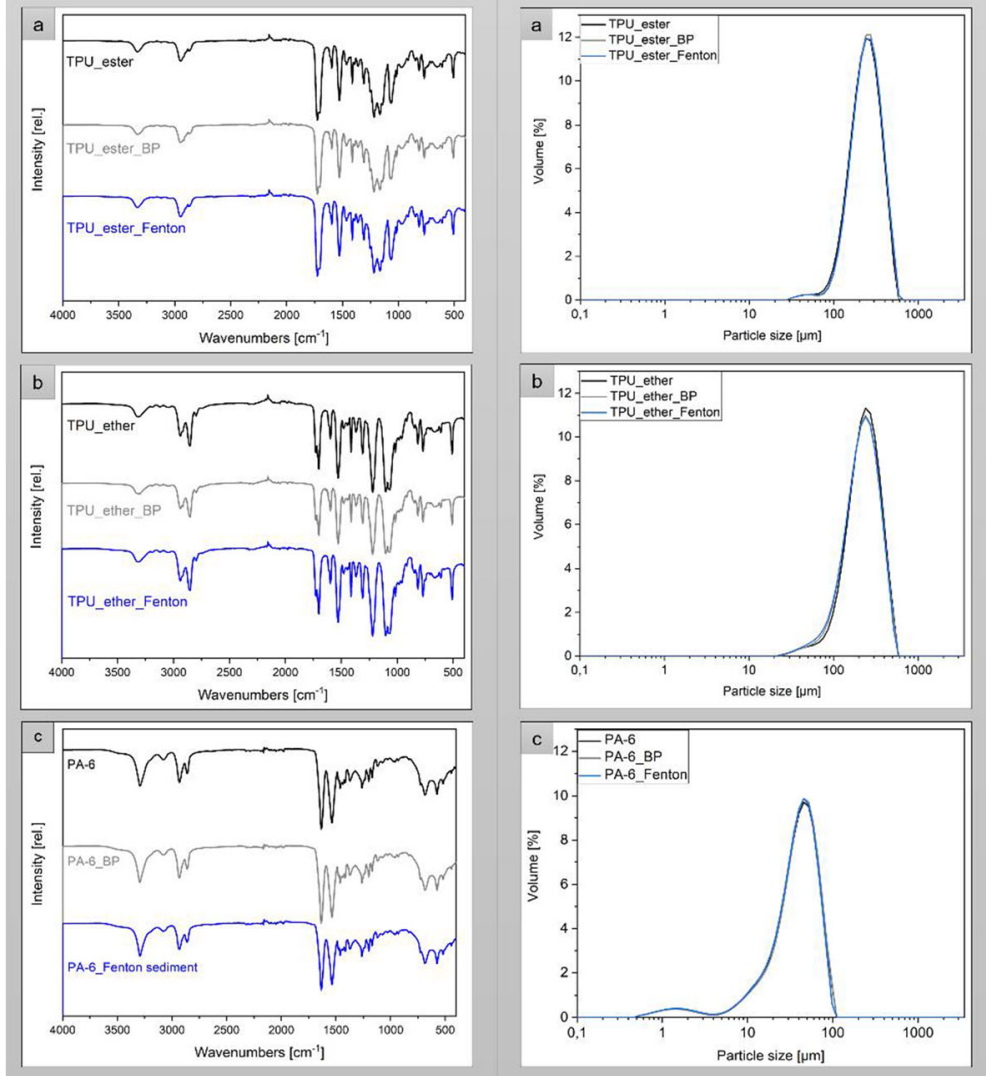

Fig. 4 Properties of engineering plastics before and after Fenton and Basic Piranha oxidation. (4.1) SEM images, (4.2) FT-IR spectra, (4.3) Particle size distributions, (a) TPU_ester, (b) TPU_ether, (c) PA-6. BP: oxidation with Basic Piranha. Fenton: oxidation using the Fenton protocol. The polymer particles showed no significant changes in their chemical compositions or particle size distributions following oxidation, but the surface textures of the TPUs were affected by the Basic Piranha oxidation

but in our own investigations the alkaline conditions during Basic Piranha oxidation had no effect on the PA6 surface texture and the chemical composition. This may have been be due to the lower concentration of our alkaline solution (3 $\mathrm{M}$ ammonium hydroxide).

\section{Tire rubber is unstable under both Fenton and Basic} Piranha oxidation

The surface texture of the tire rubber particles showed no noticeable changes after either of the oxidation protocols (Fig. 5.1), although the irregular surface structure 


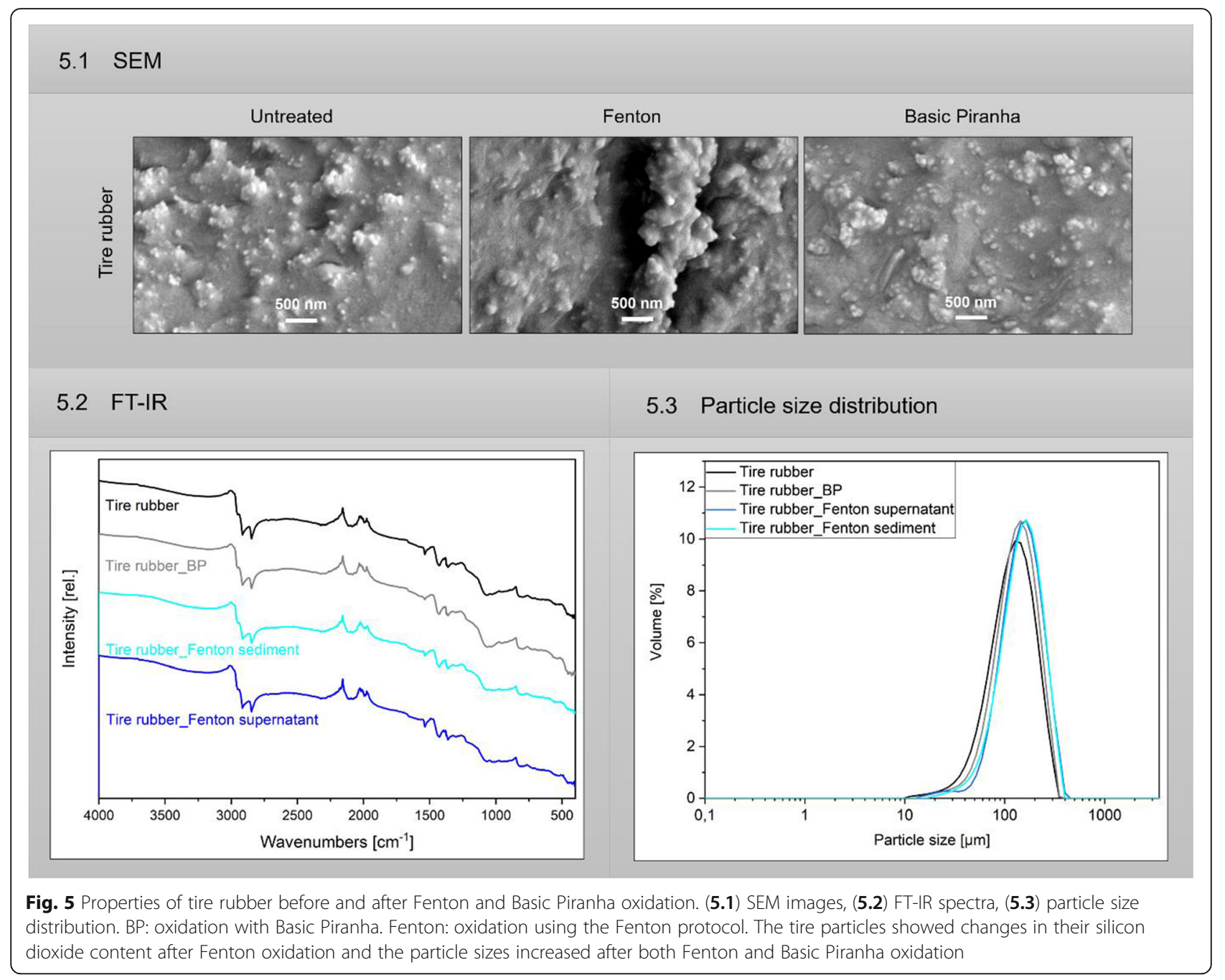

makes it difficult to analyze. The Fenton protocol led to a separation of the particles into those that floated on the surface and those that were deposited as sediment (Fig. 6). SEM images (SI Figure 7) revealed agglomerates of the particles in the supernatant but none in the sediment. Since larger particles (i.e. agglomerates) usually tend to settle, the appearance of agglomerates in the supernatant came as a surprise and was therefore further investigated using X-ray microtomography (SI Figure 8). The X-ray $\mu$-CT images of tire rubber particles showed considerable variations in the X-ray absorption by different particles due to different loadings with inorganic fillers and carbon black. Macroscopic aggregation of particles was visible following Fenton oxidation. While the pristine material consisted of a well-packed powder bed with high polydispersity and distinct variability in X-ray absorption between different particles, the settled tire rubber following oxidation revealed large-scale aggregation of particles when filtered with stable voids in the packing. Even more pronounced voids in the packing were visible for the tire particles in the supernatant following oxidation (larger agglomerates). Furthermore, an enrichment in particles with lower densities than in the original powder was detected, indicating a loss of highdensity additives during oxidation.

Tire rubber was the only material that showed any change in surface chemistry following Fenton oxidation. The particles floating on the surface of the supernatant (Fig. 5.2) showed a reduced intensity in the transmittance peaks associated with silicon dioxide at wavelengths in the range of 1130 to $975 \mathrm{~cm}^{-1}$ (Si-O asymmetric vibrations) and 470 to $400 \mathrm{~cm}^{-1}$ (Si-O symmetric vibrations) following oxidation [65-68]. The reduced silicon dioxide content supports the hypothesis that leaching of additives took place during the strong reaction during the Fenton oxidation, potentially induced by the damage of the polymer matrix. This could also explain the floating particles, with the loss of heavy 


\section{Tire rubber Basic Piranha protocol}
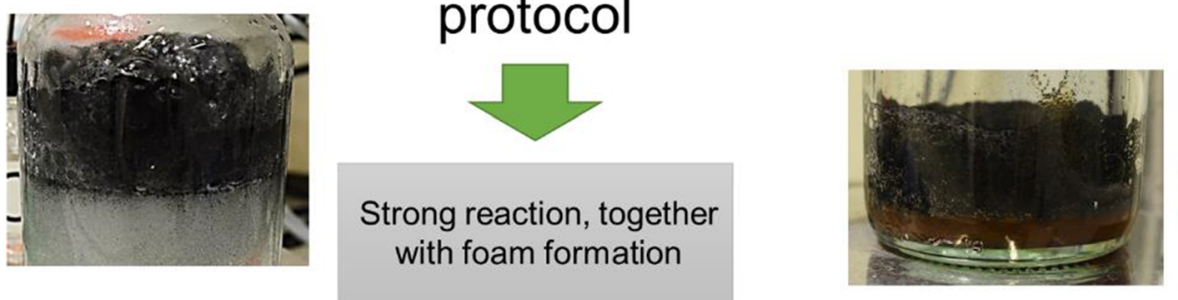

\section{Tire rubber}

Fig. 6 Reaction process during Fenton and Basic Piranha oxidation of tire rubber. After Fenton oxidation particles were separated into those floating on the surface of the supernatant and those that deposited as sediment

additives during oxidation reducing the density of the particles, enabling flotation. Silicon dioxide is often included in tire rubber for reinforcement [44, 69].

Following a very strong reaction during the Basic Piranha oxidation (Fig. 6), there was a slight shift towards larger particle sizes indicating swelling and hence changes to the tire rubber particle properties (Fig. 5.3), or even leaching of additives. Since the Fenton oxidation did not have any significant impact on the other polymers investigated, the observed strong reaction of tire rubber (which included foam formation) was not anticipated. The tire rubber particle size distributions for the supernatant float and the sediment following Fenton oxidation were almost identical (Fig. 5.3). SI Table 2b shows a higher Dx50 value for the tire rubber particles in the sediment $(+30.0 \%)$ than for the initial particles. The investigated tire rubber particles were based on polybutadiene and polyisoprene, as determined by pyrolysis gas chromatography (SI Figure 9, SI Table 3). These polymer components contain unsaturated carbon double bonds that can be easily oxidized, leading to dihydroxylation and deterioration of the polymer properties $[59,70]$. The strong reaction and increase in particle sizes may indicate exothermic reactions that lead to dihydroxylated double bonds, or alternatively, may suggest leaching and oxidation of additives. However, the dihydroxylation is not reflected in the FT-IR spectrum: Containing a large amount of carbon black the FT-IR analysis of tire rubber is challenging and therefore less reliable. Still it could be possible that only the additives are affected by the oxidation protocols and the rubber part relevant for spectroscopic or thermal microplastic detection stays unchanged.

The durable LDPE reference showed no changes in surface texture, chemical composition, or particle size distribution following either Basic Piranha or Fenton oxidation (SI Figure 2). Duplicate samples were prepared for each oxidation protocol. The observed effects of the oxidation protocols on the polymers could be confirmed in the duplicate samples (SI Figure $11+12$ ).

\section{Conclusions}

Sample preparation protocols are essential for the quantification and analysis of microplastics in natural environments, but often rely on harsh chemical treatments. Without considering the stability of microplastic particles before choosing a chemical reagent for their extraction it is impossible to know whether any micro- and nanostructures identified in the recovered microplastics were present in the original particles or induced by the sample treatment. The results of our investigations indicate that the Fenton oxidation at low temperature is more suitable than Basic Piranha oxidation for extraction of most of the microplastic particles investigated. However, for a targeted particle size related analysis of PA-6 and TPU in complex environmental matrices, Basic Piranha turned out to be a powerful alternative that could eventually be able to dissolve the organic matrix of soil samples. Since the validity of analytical results depends on the polymer type, non-targeted environmental monitoring of microplastics may be less reliable than previously assumed. The physical shape of extracted particles, as well as their chemical identity can be an artifact resulting from harsh sample preparation. The resilience of polymers to sample preparation protocols may also be reduced by degradation processes, such as photolysis or hydrolysis, experienced during their lifecycles. Targeted environmental monitoring for a specific polymer type is possible, as is targeted detection in physiological tissue, but strict controls are required for the particular combination of polymer type and sample preparation protocol used. For example, although biodegradable polymers degrade more easily than common polymers, we have been able to identify a particular digestion protocol that has no effect on the surface texture and chemical composition of biodegradable particles. However, a slight change in the particle size distribution after Fenton oxidation must be taken into account if a particle size related microplastic analysis is of interest. Still, this opens up the possibility of a more reliable evaluation of the degradation and fragmentation of 
biodegradable polymers. Unexpectedly, our analytics indicated that both of the investigated oxidation protocols affected the tire rubber particles, raising concerns about the validity of monitoring studies, and pointing to a need to develop non-destructive extraction protocols with appropriate analytic methods that affect neither the polymer matrix of rubber tires, nor the contained additives.

\section{Abbreviations}

BP: Basic Piranha; BSE: Back scattered electrons; ECHA: European Chemical Agency; EDXS: Energy dispersive X-ray spectroscopy; FT-IR: Fourier-transform infrared spectroscopy; GPC: Gel permeation chromatography; LDPE: Low density polyethylene; $\mu-C T$ : X-ray microtomography; PA: Polyamide; PBAT: Polybutylene adipate terephthalate; PBS: Polybutylene succinate; PLA: Polylactide; Pyr-GCMS: Pyrolysis gas chromatography - mass spectrometry; SEM: Scanning electron microscopy; TPU: Thermoplastic polyurethane

\section{Supplementary Information}

The online version contains supplementary material available at https://doi. org/10.1186/s43591-021-00009-9.

\section{Additional file 1.}

\section{Acknowledgements}

This publication would not have been possible without the dedicated laboratory support of Marion Wagner and Stefan Salipur. The authors are also sincerely grateful to Stephan Dohmen and Timo Witt for selecting the investigated polymers and to Ed Manning for proofreading this study.

\section{Authors' contributions}

The authors read and approved the final manuscript. PP and CR carried out the experiments for this study. PP wrote the manuscript with support from SJ, WW, TH, LM (FT-IR), UH (SEM), NN ( $\mu-C T), C L(G P C)$ and TG (pyr-GCMS). SJ, WW and TH supervised the project.

\section{Funding}

This work was partially funded by the BMBF (German Federal Ministry of Education and Research) project entitled InnoMat. Life - Innovative materials: safety in lifecycle (03XP0216X)

\section{Availability of data and materials}

All data generated or analyzed during this study are included in this published article [and its supplementary information files].

\section{Declarations}

\section{Competing interests}

Some of the authors are employees of BASF, a company producing and marketing polymers, including plastics.

\section{Author details}

${ }^{1}$ BASF SE, Carl-Bosch-Str. 38, 67056 Ludwigshafen, Germany. ${ }^{2}$ Department of Environmental Geosciences, Centre for Microbiology and Environmental Systems Science, University of Vienna, Althanstrasse 14, 1090 Vienna, Austria. ${ }^{3}$ Present address: Technical University Munich, Arcisstrasse 21, 80333 Munich, Germany.

Received: 28 January 2021 Accepted: 3 June 2021

Published online: 22 June 2021

\section{References}

1. PlasticsEurope. Plastics - the facts 2019: An analysis of European plastics production, demand and waste data. https://www.plasticseurope.org. Accessed 06 March 2020

2. Ryan PG, Moloney CL. Marine litter keeps increasing. Nature. 1993;361(6407): 23. https://doi.org/10.1038/361023a0.
3. Thompson RC, Olsen Y, Mitchell RP, Davis A, Rowland SJ, John AWG, et al. Lost at sea: where is all the plastic? Science. 2004;304(5672):838. https://doi. org/10.1126/science.1094559.

4. Derraik JGB. The pollution of the marine environment by plastic debris: a review. Mar Pollut Bull. 2002;44(9):842-52. https://doi.org/10.1016/S0025-32 6X(02)00220-5.

5. Backhaus T, Wagner M. Microplastics in the environment: much ado about nothing? A Debate Global Challenges. 2019;4(6):1900022. https://doi.org/1 $0.1002 / g c h 2.201900022$

6. Bertling J, Bertling R, Hamann L. Kunststoffe in der Umwelt: Mikro- und Makroplastik. Fraunhofer-Institut für Umwelt-, Sicherheits- und Energietechnik UMSICHT (hrsg.), Oberhausen; 2018.

7. Andrady AL. The plastic in microplastics: a review. Mar Pollut Bull. 2017; 119(1):12-22. https://doi.org/10.1016/j.marpolbul.2017.01.082.

8. Microbead-Free Waters Act of 2015. PUBLIC LAW 114-114. 2015:129 STAT. 3129

9. ECHA. Annex XV Restriction Report: Intentionally added microplastics. 2019; Version 1.2

10. Katsnelson A. News feature: microplastics present pollution puzzle. PNAS. 2015;112(18):5547-9. https://doi.org/10.1073/pnas.1504135112.

11. Mitrano DM, Wohlleben W. Microplastic regulation should be more precise to incentivize both innovation and environmental safety. Nature Communications. 2020;11(1). https://doi.org/10.1038/s41467-020-19069-1.

12. Nelson TF, Remke SC, Kohler H-PE, McNeill K, Sander M. Quantification of synthetic polyesters from biodegradable mulch films in soils. Environ Sci Technol. 2020;54(1):266-75. https://doi.org/10.1021/acs.est.9b05863.

13. de Souza Machado AA, Lau CW, Kloas W, Bergmann J, Bachelier JB, Faltin E, et al. Microplastics can change soil properties and affect plant performance. Environ Sci Technol. 2019;53(10):6044-52. https://doi.org/10.1021/acs.est. 9b01339.

14. Hu Y, Gong M, Wang J, Bassi A. Current research trends on microplastic pollution from wastewater systems: a critical review. Rev Environ Sci Biotechnol. 2019;18(2):207-30. https://doi.org/10.1007/s11157-019-09498-w.

15. Miller ME, Kroon FJ, Motti CA. Recovering microplastics from marine samples: a review of current practices. Mar Pollut Bull. 2017;123(1-2):6-18. https://doi.org/10.1016/j.marpolbul.2017.08.058.

16. Alimba CG, Faggio C. Microplastics in the marine environment: current trends in environmental pollution and mechanisms of toxicological profile. Environ Toxicol Pharmacol. 2019;68:61-74. https://doi.org/10.1016/j.etap.201 9.03.001.

17. Koelmans AA, Mohamed Nor NH, Hermsen E, Kooi M, Mintenig SM, De France J. Microplastics in freshwaters and drinking water: critical review and assessment of data quality. Water Res. 2019;155:410-22. https://doi.org/10.1 016/j.watres.2019.02.054

18. Li J, Liu H, Chen JP. Microplastics in freshwater systems: a review on occurrence, environmental effects, and methods for microplastics detection. Water Res. 2018;137:362-74. https://doi.org/10.1016/j.watres.2017.12.056.

19. Simon M, van Alst N, Vollertsen J. Quantification of microplastic mass and removal rates at wastewater treatment plants applying focal plane Array (FPA)-based Fourier transform infrared (FT-IR) imaging. Water Res. 2018;142: 1-9. https://doi.org/10.1016/j.watres.2018.05.019.

20. Li X, Chen L, Ji Y, Li M, Dong B, Qian G, et al. Effects of chemical pretreatments on microplastic extraction in sewage sludge and their physicochemical characteristics. Water Res. 2020;171:115379. https://doi. org/10.1016/j.watres.2019.115379.

21. Mitrano DM, Beltzung A, Frehland S, Schmiedgruber M, Cingolani A, Schmidt F. Synthesis of metal-doped nanoplastics and their utility to investigate fate and behaviour in complex environmental systems. Nat Nanotechnol. 2019;14(4):362-8. https://doi.org/10.1038/s41565-018-0360-3.

22. Möller JN, Löder MGJ, Laforsch C. Finding microplastics in soils: a review of analytical methods. Environ Sci Technol. 2020;54(4):2078-90. https://doi. org/10.1021/acs.est.9b04618.

23. Gündoğdu S, Çevik C, Güzel E, Kilercioğlu S. Microplastics in municipal wastewater treatment plants in Turkey: a comparison of the influent and secondary effluent concentrations. Environmental Monitoring and Assessment. 2018;190(11). https://doi.org/10.1007/s10661-018-7010-y.

24. Foekema EM, De Gruijter C, Mergia MT, Andries van Franeker J, Murk AJ, Koelmans AA. Plastic in North Sea fish. Environ Sci Technol. 2013:47(15): 8818-24. https://doi.org/10.1021/es400931b.

25. Hurley RR, Lusher AL, Olsen M, Nizzetto L, Validation of a method for extracting microplastics from complex, organic-rich. Environ Matrices 
Environ Sci Technol. 2018;52(13):7409-17. https://doi.org/10.1021/acs.est. 8 b01517.

26. Lang $M, Y u X, L i u$ J, Xia T, Wang $T$, Jia $H$, et al. Fenton aging significantly affects the heavy metal adsorption capacity of polystyrene microplastics. Sci Total Environ. 2020;722:137762. https://doi.org/10.1016/ j.scitotenv.2020.137762.

27. Munno K, Helm PA, Jackson DA, Rochman C, Sims A. Impact of temperature and selected chemical digestion methods on microplastic particles. Environ Toxicol Chem. 2018;37(1):91-8. https://doi.org/10.1002/etc.3935.

28. Babuponnusami A, Muthukumar K. A review on Fenton and improvements to the Fenton process for wastewater treatment. J Environ Chem Eng. 2014; 2(1):557-72. https://doi.org/10.1016/j.jece.2013.10.011.

29. Gnann M, Gregor C-H, Schelle S. Chemisch-oxidatives Verfahren zur Reinigung hochbelasteter Abwässer (DE 4134003 A1). Deutsches Patentamt 1993.

30. Lin SH, Lo CC. Fenton process for treatment of Desizing wastewater. Water Res. 1997;31(8):2051-6. https://doi.org/10.1016/S0043-1354(97)00024-9.

31. Avio CG, Gorbi S, Regoli F. Experimental development of a new protocol for extraction and characterization of microplastics in fish tissues: first observations in commercial species from Adriatic Sea. Mar Environ Res. 2015;111:18-26. https://doi.org/10.1016/j.marenvres.2015.06.014.

32. Mintenig SM, Int-Veen I, Löder MGJ, Primpke S, Gerdts G. Identification of microplastic in effluents of waste water treatment plants using focal plane array-based micro-Fourier-transform infrared imaging. Water Res. 2017;108: 365-72. https://doi.org/10.1016/j.watres.2016.11.015.

33. Sujathan S, Rosenwinkel K-H, Kniggendorf A-K, Nogueira R. Heat and bleach: a cost-efficient method for extracting microplastics from return activated sludge. Arch Environ Contam Toxicol. 2017;73(4):641-8. https://doi.org/10.1 007/s00244-017-0415-8.

34. Nuelle M-T, Dekiff JH, Remy D, Fries E. A new analytical approach for monitoring microplastics in marine sediments. Environ Pollut. 2014;184:1619. https://doi.org/10.1016/j.envpol.2013.07.027.

35. Kern W, Puotinen DA. Cleaning solutions based on hydrogen peroxide for use in silicon semiconductor technology. RCA Review. 1970;31(2):187-206.

36. Zhao C, Qiao X, Shao Q, Hassan M, Ma Z, Yao L. Synergistic effect of hydrogen peroxide and ammonia on lignin. Ind Crop Prod. 2020;146: 112177. https://doi.org/10.1016/j.indcrop.2020.112177.

37. Itano M, Kern FW, Miyashita M, Ohmi T. Particle removal from silicon wafer surface in wet cleaning process. Trans Semiconduct Manufact. 1993;6(3): 258-67. https://doi.org/10.1109/66.238174

38. Pan TM, Lei TF, Chao TS, Liaw MC, Ko FH, Lu CP. One-step cleaning solution to replace the conventional RCA two-step cleaning recipe for Pregate oxide cleaning. J Electrochem Soc. 2001;148(6):G315-G20. https://doi.org/10.114 9/1.1369374.

39. Catarino Al, Thompson R, Sanderson W, Henry TB. Development and optimization of a standard method for extraction of microplastics in mussels by enzyme digestion of soft tissues. Environ Toxicol Chem. 2017; 36(4):947-51. https://doi.org/10.1002/etc.3608.

40. von Friesen LW, Granberg ME, Hassellov M, Gabrielsen GW, Magnusson K. An efficient and gentle enzymatic digestion protocol for the extraction of microplastics from bivalve tissue. Mar Pollut Bull. 2019;142:129-34. https:// doi.org/10.1016/j.marpolbul.2019.03.016.

41. Tagg AS, Sapp M, Harrison JP, Ojeda JJ. Identification and quantification of microplastics in wastewater using focal plane Array-based reflectance micro-FT-IR imaging. Anal Chem. 2015;87(12):6032-40. https://doi.org/10.1 021/acs.analchem.5b00495

42. Cole M, Webb H, Lindeque PK, Fileman ES, Halsband C, Galloway TS. Isolation of microplastics in biota-rich seawater samples and marine organisms. Sci Rep. 2014;4:4528. https://doi.org/10.1038/srep04528.

43. Herrera A, Garrido-Amador P, Martinez I, Samper MD, Lopez-Martinez J, Gomez M, et al. Novel methodology to isolate microplastics from vegetalrich samples. Mar Pollut Bull. 2018;129(1):61-9. https://doi.org/10.1016/j.ma rpolbul.2018.02.015.

44. Zimmermann T, Jepsen D, Reihlen A. Use of nanomaterials in tires environmental relevance and emissions: ÖKOPOL GmbH - Institut für Ökologie und Politik; NanoDialogue of the German Government, Topical Report, 2018.

45. Gottipolu RR, Landa ER, Schladweiler MC, McGee JK, Ledbetter AD, Richards $\mathrm{JH}$, et al. Cardiopulmonary responses of Intratracheally instilled Tire particles and constituent metal components. Inhal Toxicol. 2008;20(5):473-84. https:// doi.org/10.1080/08958370701858427.
46. Künkel A, Becker J, Börger L, Hamprecht J, Koltzenburg S, Loos R, et al. Polymers, biodegradable. Ullman's Encyclopedia of Industrial Chemistry; Wiley 2016:1-29.

47. Gross RA, Kalra B. Biodegradable polymers for the environment. Green Chem. 2002;297:803-7. https://doi.org/10.1126/science.297.5582.803.

48. Al-Azzawi MSM, Kefer S, Weißer J, Reichel J, Schwaller C, Glas K, et al. Validation of Sample Preparation Methods for Microplastic Analysis in Wastewater Matrices-Reproducibility and Standardization. Water. 2020;12(9). https://doi.org/10.3390/w12092445.

49. BASF SE. Thermoplastic Polyurethane Elastomers (TPU) - Elastollan Chemical Properties www.elastollan.de. Accessed 11 April 2020.

50. Gilbert M. Brydson's Plastics Materials: Elsevier Inc.; 2017.

51. Masura J, Baker J, Foster G, Arthur G. Laboratory methods for the analysis of microplastics in the marine environment: recommendations for quantifying synthetic particles in waters and sediments. NOAA Technical Memorandum NOS-OR\&R-48. 2015

52. Lofrano G, Meriç S, Belgiorno V, Napoli RMA. Fenton's oxidation of variousbased tanning materials. Desalination. 2007;211(1-3):10-21. https://doi.org/1 0.1016/j.desal.2006.03.589.

53. Al Mgheer T, Abdulrazzak FH. Oxidation of multi-walled carbon nanotubes in acidic and basic piranha mixture. Front Nanosci Nanotechnol. 2016;2(4): 155-8. https://doi.org/10.15761/FNN.1000127.

54. Ghosal S, Chen M, Wagner J, Wang ZM, Wall S. Molecular identification of polymers and anthropogenic particles extracted from oceanic water and fish stomach - a Raman micro-spectroscopy study. Environ Pollut. 2018;233: 1113-24. https://doi.org/10.1016/j.envpol.2017.10.014.

55. Malvern Panalytical. Mastersizer 3000 - Die intelligente Partikelgrößenbestimmung. https://www.malvernpanalyticalcom/de/ products/product-range/mastersizer-range/mastersizer-3000. Accessed 12 May 2020.

56. Lunt J. Large-scale production, properties and commercial applications of polylactic acid polymers. Polym Degrad Stab. 1998;59(1-3):145-52. https:// doi.org/10.1016/S0141-3910(97)00148-1.

57. Witt U, Müller R-J, Deckwer W-D. Evaluation of the biodegradability of Copolyesters containing aromatic compounds by investigations of model oligomers. J Environ Polymer Degradation. 1996;4(1):9-20. https://doi.org/1 0.1007/BF02083878

58. Müller R-J, Witt U, Rantze E, Deckwer W-D. Architecture of containing biodegradable copolyesters aromatic constituents. Polym Degrad Stab. 1998:59(1-3):203-8. https://doi.org/10.1016/S0141-3910(97)00186-9.

59. Elsner $P$, Eyerer $P$, Hirth T. Kunststoffe - Eigenschaften und Anwendungen: Springer-Verlag. Heidelberg; 2012.

60. Jasmee S, Omar G, Masripan NAB, Kamarolzaman AA, Ashikin AS, Che Ani F. Hydrophobicity performance of polyethylene terephthalate (PET) and thermoplastic polyurethane (TPU) with thermal effect. Mater Res Express. 2018:5(9).

61. Scholz P, Wachtendorf V, Panne U, Weidner SM. Degradation of MDI-based polyether and polyester-polyurethanes in various environments - effects on molecular mass and crosslinking. Polym Test. 2019;77:105881. https://doi. org/10.1016/j.polymertesting.2019.04.028.

62. BASF SE. Thermoplastic polyurethane elastomers (TPU) -Elastollan ${ }^{\bullet}$ chemical resistance. 2011

63. Francisco DL, Paiva $L B$, Aldeia W. Advances in polymer nanocomposites: a review. Polym Compos. 2019;40(3):851-70. https://doi.org/10.1002/ pc.24837.

64. Jiayong C, Shuqiu Y, Huizhou L, Xiquan M, Zhichun W. New mixed solvent systems for the extraction and separation of ferric iron in sulphate solutions. Hydrometallurgy. 1992;30:401-16. https://doi.org/10.1016/0304-386X(92 ) $90096-1$.

65. Paulish AG, Dmitriev AK, Gelfand AV, Pyrgaeva SM. Absorption spectral characteristics of infrared radiation in silicon dioxide films for thermal radiation detectors. Optoelectronics Instrument Data Process. 2019;55(5): 508-12. https://doi.org/10.3103/\$8756699019050145.

66. Guo M, Kanezashi M, Nagasawa H, Yu L, Yamamoto K, Gunji T, et al. Tailoring the microstructure and permeation properties of bridged organosilica membranes via control of the bond angles. J Membr Sci. 2019;584:56-65. https://doi.org/10.1016/j.memsci.2019.04.072.

67. Musić S, Filipović-Vinceković N, Sekovanić L. Precipitation of amorphous $\mathrm{SiO}_{2}$ particles and their properties. Braz J Chem Eng. 2011;28(1):89-94. https://doi.org/10.1590/S0104-66322011000100011. 
68. Gillespie RJ, Robinson EA. Characteristic vibrational frequencies of compounds containing Si-O-Si, P-O-P, S-O-S, and cl-O-cl bridging groups. Can J Chem. 1964;42(11):2496-503. https://doi.org/10.1139/ v64-366.

69. Ash M. Handbook of fillers, extenders, and diluents: synapse information resources, U.S.; 1998.

70. Koltzenburg S, Maskos M, Nuyken O. Polymere: Synthese, Eigenschaften und Anwendungen, Springer-Verlag. Berlin Heidelberg; 2014.

\section{Publisher's Note}

Springer Nature remains neutral with regard to jurisdictional claims in published maps and institutional affiliations.

\section{Submit your manuscript to a SpringerOpen ${ }^{\circ}$ journal and benefit from:}

- Convenient online submission

- Rigorous peer review

- Open access: articles freely available online

- High visibility within the field

- Retaining the copyright to your article

Submit your next manuscript at $\boldsymbol{\sim}$ springeropen.com 